\title{
Assessment of in vitro Multiplication of Lemna minor in the Presence of Phenol: Plant/Bacteria System for Potential Bioremediation - Part I
}

\author{
Olga Radulović ${ }^{1 *}$, Marija Petrić2, Martin Raspor ${ }^{2}$, Vojin Tadić ${ }^{3}$, \\ Petar Jovanović ${ }^{4}$, Vladan Zečević ${ }^{5}$ \\ ${ }^{1}$ Institute for Chemistry, Technology and Metallurgy, Njegoševa 12, Belgrade, Serbia \\ 2Department for Plant Physiology, Institute for Biological Research "Siniša Stanković", \\ Bulevar Despota Stefana 152, Belgrade, Serbia \\ ${ }^{3}$ Mining and Metallurgy Institute Bor, Zeleni bulevar 35, Bor, Serbia \\ ${ }^{4}$ Institute of General and Physical Chemistry, Studentski Trg 12-16, Belgrade, Serbia \\ ${ }^{5}$ Faculty of Engineering and International Management, Carigradska 28, Belgrade, Serbia
}

Received: 27 November 2017

Accepted: 30 January 2018

\begin{abstract}
The aim of this work was to examine the multiplication of the common duckweed (Lemna minor), an aquatic plant species widespread in European stagnant waters, in two different media (Murashige - Skoog and Hoagland) with and without phenol supplementation. In order to quantify plant multiplication we have used relative growth rate and tolerance indices on both tested media and at five phenol concentrations $(10,15,20,30 \mathrm{and} 100 \mathrm{mg} / \mathrm{L})$. Furthermore, we examined the possibility of phenol removal from aqueous media containing different phenol concentrations, by using plant/bacteria system consisting of the duckweed and its naturally occurring microbial populations. After 7 days, number of newly formed fronds was approximately four times higher than at the beginning of the experiment on both tested media. The most important result in this study was removal of $70 \%$ of phenol from the highest initial concentration of $100 \mathrm{mg} / \mathrm{L}$, in mixed cultures of duckweed and bacteria. By comparison, aseptic duckweed cultures removed approximately $50 \%$ of phenol at the same initial concentration. Our duckweed specimen showed a fast reproduction rate, high tolerance to phenol and a possible cooperation with rhizosphere-associated bacteria. All of these traits can be ultimately utilized for bioremediation purposes.
\end{abstract}

Keywords: phytoremediation, bioremediation, phenol, rhizosphere, Lemna minor

*e-mail: o.radulovic@ihtm.bg.ac.rs 


\section{Introduction}

Duckweed (Lemnaceae) is a monocotyledonous aquatic plant endemic to water bodies such as lakes and ponds on most continents. Among five genera with 37 species, the genus Lemna is comprised of 13 species usually described as tiny floating aquatic plants with simplified morphology and a high biomass production rate [1]. Duckweed is an example of neoteny in higher plants, implying that they do not develop the shoot apical meristem and consequently form a frond, a hybrid tissue derived from leaf and stem precursor tissues [2]. In Lemna spp., each frond is connected to a single root [3]. Reproduction is dominantly vegetative and highly efficient, whereby each frond produces 4-12 daughter fronds during its 4-5-week-long life, which helps duckweed spread quickly over water surfaces [4]. Fast vegetative reproduction, along with the ability to accumulate inorganic and organic toxic substances, provides duckweed with great potential for remediation of waters polluted with macronutrients, organic xenobionts, and inorganic pollutants such as heavy metals, arsenic, and selenium [3] which is a process defined as bioremediation or, specifically, phytoremediation. Duckweed biomass can be harvested after bioremediation and used for biofuel, fertilizer, or fodder, depending on its previous exposure to pollutants or nutrients. It has been suggested that duckweed has greater potential for application in wastewater bioremediation and biomass production than other fast-spreading water species such as water hyacinth (Eichhornia crassipes) [5].

Interplay of Bacteria and Duckweed in Bioremediation of Phenol Contamination

There have been attempts to assess the phytoremediation potential of duckweed [6], and while some of the remediation potential can be attributed exclusively to its metabolical activity, an important role in detoxification of wastewaters has been credited to the microorganisms inhabiting its rhizosphere - most prominently bacteria. Bioremediation may be conducted by the bacteria alone $[7-8]$ or conversely by plants alone; however, the process is greatly enhanced with plants and bacteria combined [8-9], which implies the cooperative nature of interactions between the bacteria and their duckweed host. Additionally, Toyama et al. have proven that phenolic exudates of the giant duckweed attract phenol-degrading bacteria regardless of the extrinsic phenol in the bulk water [10], prompting the researchers even further to find the appropriate phenol-degrading bacteria within the rhizosphere.

\section{Potential of Biological Decontamination} of Phenolic Pollution in Ambient Waters

Phenolic compounds are very toxic industrial products that are hazardous to all aquatic species and to human health as well. In fact, even diluted phenol solutions can cause accute poisoning [11]. Phenol elimination was definitely confirmed using two strains of rhizosphereassociated bacteria: Acinetobacter calcoaceticus and Pseudomonas fluorescens [8, 12-13]. Wastewater of industrial origin (pharmaceuticals, plastics, dyes, paper) usually contains high levels of phenolic compounds. Therefore, phenol-contaminated industrial wastewaters are strictly forbidden from being released into free river flow without prior treatment and decontamination, although the constant leakage of small amounts of phenolic compounds remains an alarming problem worldwide, especially in developing countries (including the Balkans) [13-15]. Standard physical and chemical methods of decontamination (Fenton oxidation, UV radiation, ozonization, etc.) are effective but expensive, and may produce other toxic byproducts. In light of this restriction, biological methods of decontamination are considered to be a preferable substitute and/or a highly desirable finishing polishing step: biological decontamination is more sustainable and effective longterm [16-18]; additionally, the utilization of autochthonic, non-invasive, and non-pathogenic organisms preserves and restores the natural balance of the contaminated site [16]. Consequently, further studies on the potential application of European-widespread species, common duckweed (L. minor) in wastewater remediation is needed. This work represents the first step toward constructing a biculture-based plant-bacterial system for in vitro analysis of bioremediation of contaminated surface waters. To this end, we conducted: (1) surface sterilization and in vitro cultivation of sterilized L. minor plants and (2) test of phenol removal using both surface-sterilized and non-sterile fronds.

\section{Experimental Procedure}

\section{Preparing Plant Material}

Duckweed plants (Lemna minor L.) were collected from a pond in the garden of the Siniša Stanković Institute for Biological Research, University of Belgrade. Plants were washed with tap water for 20 min and afterward surface-sterilized in commercial bleach solution containing $5 \%(\mathrm{v} / \mathrm{v})$ sodium hypochlorite for $5 \mathrm{~min}$, followed by washing with sterile distilled water three times. Plants (2-4) were placed on two standard nutrient media for in vitro plant cultivation: Murashige and Skoog medium with complete micro- and macronutrient formulation [19] or on typical Hoagland-Arnon medium [20], both made with $30 \mathrm{~g} / \mathrm{L}$ sucrose and $\mathrm{pH} 6.2$, to allow frond regeneration. Nutrient medium was made without agar (liquid medium). For non-aseptic cultures, plants were taken directly from the pond using instruments for aseptic culture, and washed three to five times in Petri dishes with sterile water before being transferred to sterile media without performing surface sterilization, in order to keep the original rhizosphere microorganisms while washing off casual contaminants. Both aseptic 
and non-aseptic plants were grown at $+24 \pm 2^{\circ} \mathrm{C}$ (under fluorescent light of $40 \mu \mathrm{mol} \mathrm{m} \mathrm{m}^{-2} \mathrm{~s}^{-1} 16 \mathrm{~h}$ light $/ 8$ $\mathrm{h}$ dark photoperiod). Daughter fronds derived from a ingle mother frond were kept and maintained as stock cultures. The number of new plants was measured on both nutrient media. The experiment was performed in three replicates for each medium. Bacterial cultures associated with the rhizosphere were subsequently isolated by submerging approximately 10 fronds into $5 \mathrm{~mL}$ of lysogeny broth (LB) liquid medium, which was then streaked and re-streaked on LB solid agar until purity of the colony has been achieved [21]. Pure strains were transferred to MacConkey agar and cultivated at ambient temperature overnight or until growth was observed [22].

\section{Effect of Media Composition on in vitro Growth of L. minor}

Each replicate contained sterile fronds grown in cylindrical bottles (4 $\mathrm{cm}$ in diameter) containing $40 \mathrm{~mL}$ of liquid medium with randomly chosen 4 fronds. The number of fronds was observed every two days for 7 days. Biomass production was calculated after 20 days of growth on both nutrient media. Prior to biomass measuring, plants were transferred onto filter paper and left to dry for 1 minute.

L. minor relative growth rates, RGR $\left(\mathrm{g} \cdot \mathrm{g}^{-1}\right.$ day $\left.^{-1}\right)$ were calculated according to the equation (Eq. 1):

$$
\left(\ln W_{2}-\ln W_{2}\right) /\left(T_{2}-T_{1}\right)
$$

...where $W_{1}, T_{1}$, and $W_{2}, T_{2}$ are initial and final dry weights and times for each treatment, respectively [23]. Tolerance index (Ti) was calculated according to (Eq. 2) [24]:

\section{Dry plant weight (phenol grown) / Dry plant weight (control)}

\section{Study of the Effect of Phenol on Lemna minor \\ Growth and Possibility of Phenol Removal from the Medium}

Nutrient medium was supplemented with phenol: final concentrations of $10,15,20,30$, and $100 \mathrm{mg} / \mathrm{l}$, respectively. Control plants were grown in medium without the addition of phenol. Non-sterile plants (picked directly from pond) were used as a model for investigating phenol removal with the natural "as is" rhizosphere community. Cultivation was performed at $24 \pm 2^{\circ} \mathrm{C}$. Samples $(2 \mathrm{~mL})$ of liquid nutrient medium were collected every day during five days of cultivation. Pure nutrient medium without phenol was used as blank control. Determining intrinsic phenol concentration was done in medium without artificially added phenol after 1 day. Further, aseptic plants and non-sterile plants were added to sterile phenol-supplemented media. Phenol concentration was determined every day over the following five days.

\section{Determining Phenol Concentration in Nutrient Medium}

Determining the concentration of phenol in water was done spectrophotometrically with the use of 4-aminoantipyrine (4-AAP). Samples were treated with phosphoric acid at $\mathrm{pH} 4.0$, and then distilled prior to spectrophotometric measurement. All measurements were performed at $+25^{\circ} \mathrm{C}$.

The mixture prepared for the measurement of the concentration of phenol in water contained a distilled sample, buffer (16.9 g ammonium chloride dissolved in $143 \mathrm{~mL}$ of ammonium hydroxide, $\mathrm{pH} 10$ ), $2 \mathrm{~mL}$ of 4-AAP solution ( $2 \mathrm{~g}$ of 4 -AAP dissolved in $100 \mathrm{~mL}$ of distilled water), and $2 \mathrm{~mL}$ of potassium ferricyanide solution (8 $\mathrm{g} \mathrm{K}_{3} \mathrm{Fe}(\mathrm{CN})_{6}$, dissolved in $10 \mathrm{~mL}$ of distilled water). The reaction solution was mixed and after $15 \mathrm{~min}$ absorbance was measured at $460 \mathrm{~nm}$, which is the absorbance maximum for the quinone - imide adduct formed in the reaction of 4-AAP and phenol. Standards were measured at the same wavelength, and the dilutions of phenol were prepared in the concentration range from 0 to $1000 \mu \mathrm{g} / \mathrm{L}$. All measurements were made according to the regulations of the Institute for Standardization of Serbia, code of ISO 6439 B: 1997, water qualitydetermination of phenol index (Institute MOL, Stara Pazova, Serbia), and were performed on UV VIS 1166, Labomed Inc. (LA, California, USA).

\section{Statistical Analysis}

Numerical data were analyzed using the computer program Statgraphics version 4.2 (STScI Inc. and
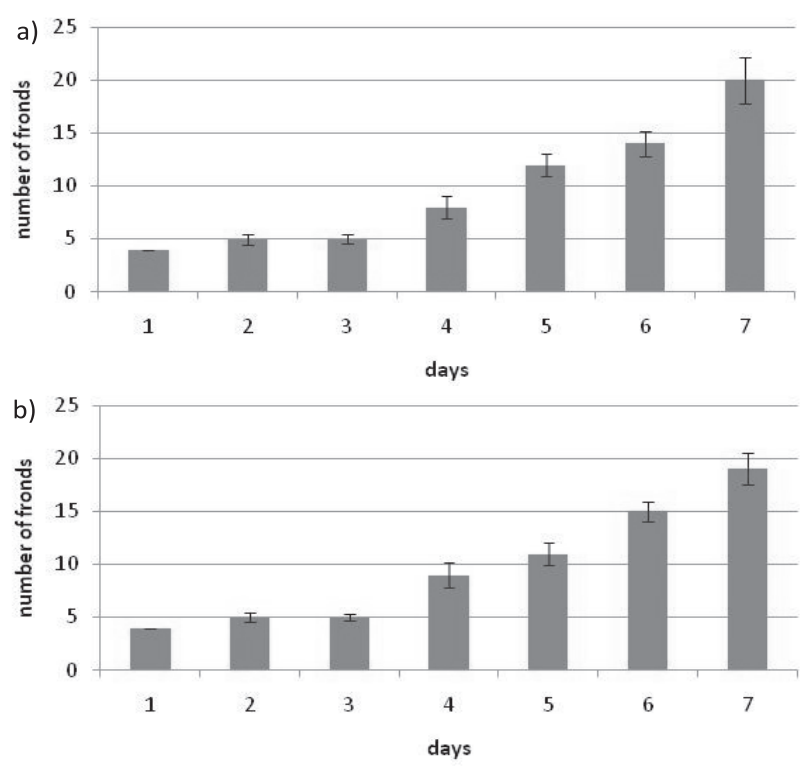

Fig. 1. Multiplication rates of duckweed cultivated on MS - and $\mathrm{H}$ - medium. 
Statistical Graphics Corporation, 1985-1989, USA). Analysis of variance (ANOVA) and least significant difference (LSD) test at $p \leq 0.05$ were used to determine statistically significant differences between mean values. The graphical representation of the results was done with Microsoft Excel.

\section{Results and Discussion}

Effects of the Two Nutrient Media (Murashige-Skoog and Hoagland) with or without Phenol on L. minor Multiplication and Morphology

MS and $\mathrm{H}$ media have similar effects on $L$. minor multiplication (Fig. 1). After 4 days of cultivation, the effects of $\mathrm{MS}$ and $\mathrm{H}$ media on multiplication of duckweed were determined as frond duplication (4 new fronds when grown on MS and 5 new fronds on $\mathrm{H})$. After 7 days, the number of newly formed fronds was about four-fold higher than at the beginning of the experiment. Newly formed plants kept their normal morphology on both tested media. Further growth on both media led to regenerating more plants at an almost geometrical rate.

Relative growth rate of $L$. minor declined with increasing phenol concentration on both media (Fig. 2). The trend in RGR decline was constant but slow, and the lowest biomass production was noticed at the highest phenol concentration (100 mg/l). RGR of $L$. minor, growing on medium with $100 \mathrm{mg} / \mathrm{l}$ of initial phenol concentration, was diminished and was $8 \%$ lower than that on medium without phenol. However, plants remained morphologically unchanged.

\section{Rhizosphere-Associated Bacteria}

To assess the diversity of bacteria associated with the roots of the non-sterile plants, we examined the Gram stain reaction and overall morphological

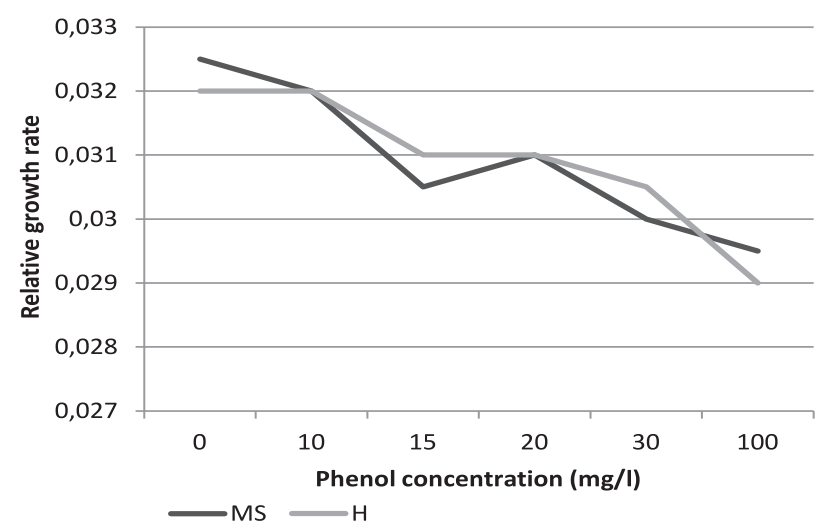

Fig. 2. Relative growth rates of duckweed cultivated on MS and $\mathrm{H}-$ medium supplemented with varying concentrations of phenol $(0-100 \mathrm{mg} / \mathrm{l})$.
Table 1. Tolerance index (Ti) relative to phenol concentration in the nutrient medium. MS=Murashige and Skoog medium; $\mathrm{H}=$ Hoagland medium

\begin{tabular}{|c|c|c|}
\hline Phenol concentration $(\mathrm{mg} / \mathrm{L})$ & $\mathrm{Ti}(\mathrm{MS})$ & $\mathrm{Ti}(\mathrm{H})$ \\
\hline 0 & $1 \pm 0.14$ & $1 \pm 0.11$ \\
\hline 10 & $0.97 \pm 0.12$ & $1.031 \pm 0.17$ \\
\hline 15 & $0.91 \pm 0.11$ & $0.96 \pm 0.11$ \\
\hline 20 & $0.92 \pm 0.10$ & $0.98 \pm 0.12$ \\
\hline 30 & $0.88 \pm 0.14$ & $0.95 \pm 0.11$ \\
\hline 100 & $0.86 \pm 0.15$ & $0.89 \pm 0.11$ \\
\hline
\end{tabular}

properties of the colonies isolated from the rhizosphere. Morphologically, Gram negative coccoid bacilli were prevalent. Based on MacConkey agar reaction, the majority of isolated cultures were enteric and lactose-fermenting. Based on light microscopy, we identified at least 6 different bacterial genera that are associated with the rhizosphere of Lemna minor: enteric bacteria (possibly Klebsiella and Enterobacter), Bacillus, Pseudomonas, Staphylococcus, and Micrococcus.

\section{Phenol - Tolerance of L. minor}

To investigate the capabililty of plants to grow in phenol-supplemented medium, the tolerance index (Ti) was calculated. As reported in Table 1, we determined Ti of $L$. minor on both examined media. It is obvious that $\mathrm{Ti}$ does not differ significantly between plants grown on MS or $\mathrm{H}$ media. Also, Ti indices of plants grown on increment concentrations of phenol did not differ significantly. Actually, Ti index remained surprisingly high even at the highest phenol concentration.

\section{Phenol - Removal Capacities of Aseptic and Non-Aseptic L. minor}

To determine the possibility of phenol removal from medium by aseptically grown $L$. minor plants and by non-sterile L. minor plants, phenol has been added to nutrient media in final concentrations: 5, 10, 15, 20, 30, and $100 \mathrm{mg} / \mathrm{l}$, respectively. Phenol in blank solution was determined after one day. Control plants were grown on medium without phenol. After 4 days, concentration of phenol in the control group (no phenol supplementation) was significantly higher in medium with non-sterile plants (more than two-fold). By day 5, phenol concentration in the control group dropped below $5 \mathrm{mg} / \mathrm{l}$, while it remained two times higher in the experimental group with nonsterile plants (Fig. 3a). Aseptic L. minor plants appeared to remove much more phenol from initial concentration of $10 \mathrm{mg} / 1$ than the mixed culture of plant and bacteria (Fig. 3b). After 5 days their phenol removal rates were equal. After only 3 days, phenol concentration in the culture of aseptic plants dropped to $50 \%$ of initial value 
(Fig. 3b). At initial concentration of $15 \mathrm{mg} / \mathrm{l}$ of phenol the non-sterile plants removed phenol more efficiently. After five days of cultivation, phenol concentration in the media with aseptic plant cultures dropped to $50 \%$ the initial value, while in the mixed cultures it dropped to $33 \%$ of the initial concentration (Fig. 3c).

At higher phenol concentrations in growth media (20 and $30 \mathrm{mg} / \mathrm{l}$ ), non-sterile plants again removed more phenol from the initial concentrations compared to aseptic plants (Figs $3 \mathrm{~d}$ and 3e). At the highest initial concentration of phenol $(100 \mathrm{mg} / \mathrm{l})$, non-sterile plants were significantly more efficient in removing phenol than aseptic plant cultures (Fig. 3f). After five days of cultivation at $100 \mathrm{mg} / \mathrm{l}$, phenol concentration dropped from 100 to $30 \mathrm{mg} / \mathrm{l}$ in non-sterile cultures.

Common Duckweed (L. minor) is a Promising

Phenol - Eliminating the Plant, and the Process

is Enhanced in the Presence of the Rhizosphere - Associated Microbial Population

We have examined different media for $L$. minor growth in vitro and their impact on plant morphology and multiplication. MS and $\mathrm{H}$ media have been successfully used in agriculture, plant tissue cultivation, and duckweed cultivation $[3,25]$. Our results show that the differences in the effect two media have on frond multiplication are negligible, which might not be true for all ecotypes [25]. We have documented a doubling time of 4 days. By comparison, Ziegler et al. tested more than 400 ecotypes of the Lemnaceae family and observed the doubling time ranging from 1.34 to 4.54 days on average [3]. Yamaga et al. [8] noticed that during long-term growth, non-sterile fronds multiplied faster compared to sterile plants, regardless of phenol. We did not observe such a phenomenon. This might be a consequence of specific bacterial community composition, i.e., whether the rhizosphere is dominated by plant-growth-promoting bacteria [8]. As we observed no differences in terms of plant morphology, proliferation, and relative growth between $L$. minor plants grown on Hoagland and MS media in vitro, further experiments on phenol removal were carried out exclusively on MS media.

Relative growth rate (RGR) of L. minor declined with increasing phenol concentration in medium. The highest RGR reduction was observed when plants were a)

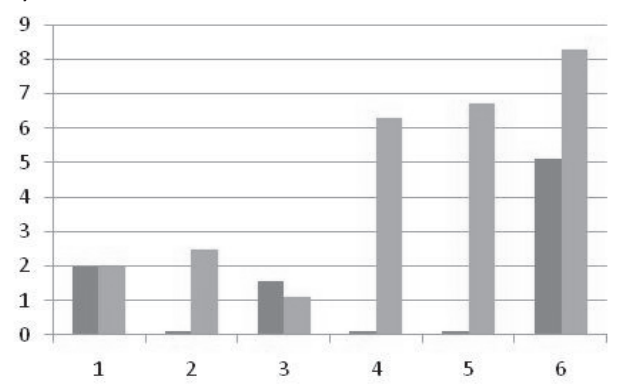

b)

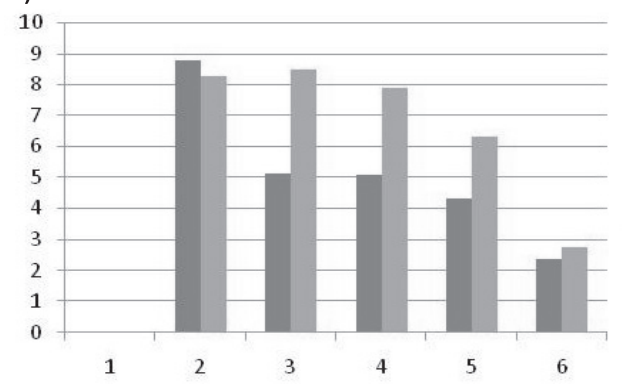

c)

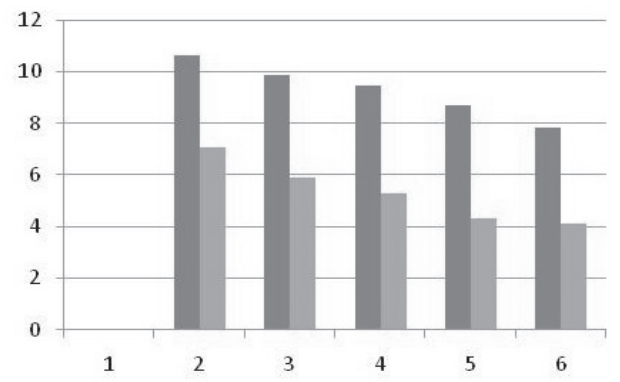

- Plants

- Plants + bacteria

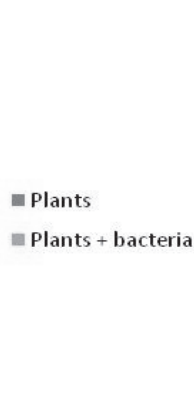

- Plants

- Plants + bacteria
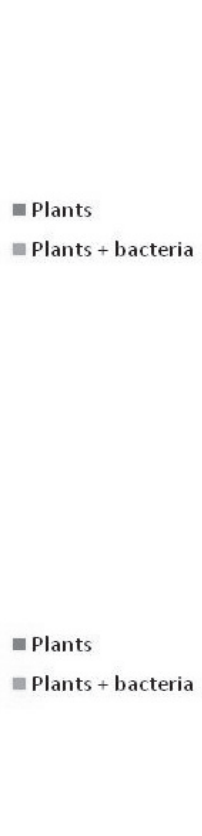

d)
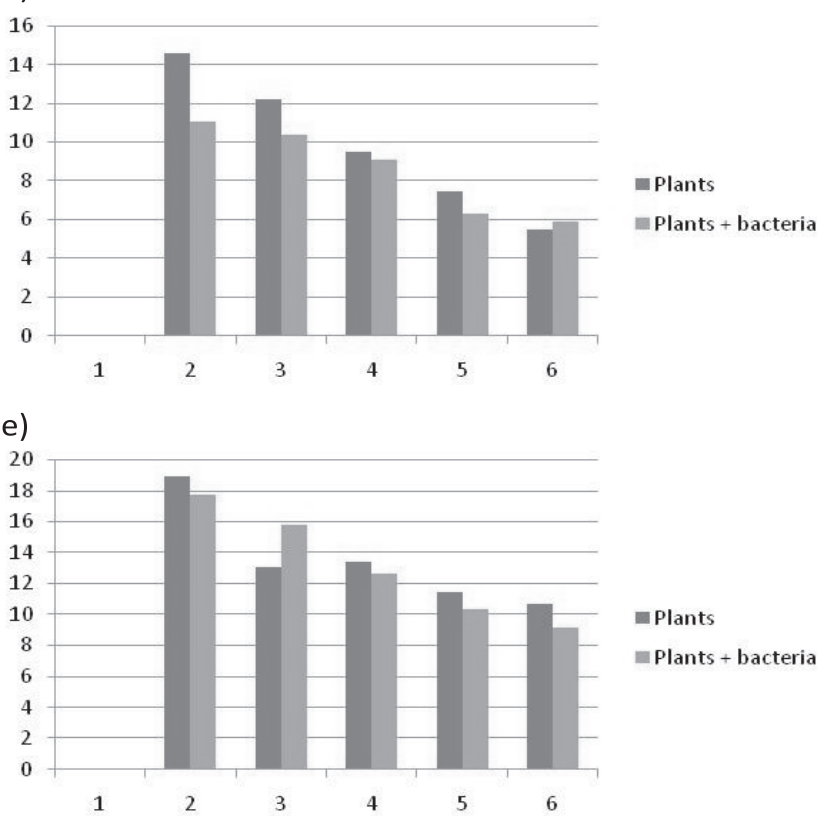

f)

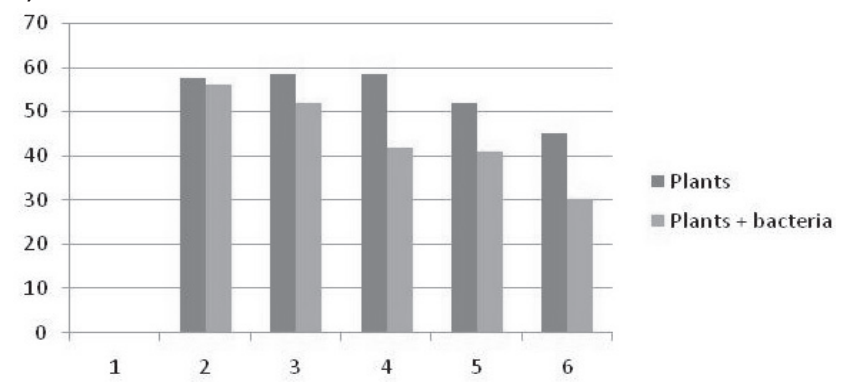

Fig. 3. Removal rate of phenol at different initial concentrations in MS - medium. A - No extrinsic phenol added. Initial concentration of phenol is: $\mathrm{B}-10 \mathrm{mg} / \mathrm{l} ; \mathrm{C}-15 \mathrm{mg} / \mathrm{L} ; \mathrm{D}-20 \mathrm{mg} / \mathrm{l} ; \mathrm{E}-30 \mathrm{mg} / \mathrm{l} ; \mathrm{F}-100 \mathrm{mg} / \mathrm{l}$. 
exposed to the highest phenol concentration $(100 \mathrm{mg} / \mathrm{l})$. Our results are in correlation with Bianconi et al. [26], where a significant decline in RGR was documented when plants of $L$. minor were exposed to high cadmium concentrations. However, L. minor population in vitro continues to multiply even at elevated phenol concentrations. Enzymatic mechanisms of phenol uptake and transformation by the plants are diverse [27-28]. Although the exact enzymatic status of our experimental plants remains to be examined, all of our plants retained a great survival rate $(100 \%)$ at all examined phenol concentrations, which suggests that L. minor has an inherent and highly active enzymatic system for phenol neutralization. These results are similar to that of Bianconi et al., where L. minor was marked as a plant with high bio-concentration factor for $\mathrm{Cd}$ and had also a remarkable survival rate [26].

The capability of plants to grow in the presence of a toxic substance is described using tolerance index (Ti). Plants are considered tolerant if their tolerance index (Ti) is higher than 0.6 [23-24, 26]. In our experiments, L. minor retained a Ti of more than 0.7 and an unchanged morphology at all tested phenol concentrations, which implies that this plant is indeed a promising bioremediation agent. On top of their simplified anatomy and one of the smallest genomes among higher plants (similar in size and organization to Arabidopsis thaliana [2]), Lemnaceae are easy to manipulate genetically in vitro, openning yet another way to enhancement of their bioremediation capacity [29].

Due to their efficient metabolism of aromatic compounds and potential of genetic transformation in vitro, bacteria are, as a group, generally regarded as efficient bioremediation organisms [8, 12, 17-18]. In our study, we have cultivated in parallel both the aseptic plants and plants associated with naturally occurring microbial populations in the rhizosphere of the duckweed, which are dominated by bacteria. Aseptic cultures of plants at the initial low phenol concentration $(10 \mathrm{mg} / \mathrm{l})$ apparently removed more phenol than mixed cultures of plants and bacteria (Fig. 3b). However, these efficiency rates may likely be the consequence of the fact that non-sterile cultures actively produced a comparably high amount of phenolic compounds and of the fact that the 4 AAP method does not discriminate between different phenolic compounds (compare with Fig. 3a). It is safe to assume that both plants and bacteria synthesize certain phenolic compounds in varying ratios (probably caffeic acid, chlorogenic acid, isochlorogenic acid, etc.), leading to falsely positive results.

According to our experiments, non-sterile fronds removed phenol more efficiently than aseptically grown fronds, and the efficiency of removal remained constant at all initial concentrations. Approximately $70 \%$ of phenol was removed after 5 days, which may suggest that the rhizosphere bacteria are not only metabolically active when exposed to phenol in the $10-100 \mathrm{mg} / \mathrm{l}$ range, but also highly resistant to phenol. Aseptic plants removed phenol with varying efficiency (approximately $50-70 \%$ of the initial phenol eliminated after 5 days). The greatest difference in elimination rates first occurred at $15 \mathrm{mg} / \mathrm{l}$ and then at $100 \mathrm{mg} / \mathrm{l}$ of initial phenol concentration (Figs 3c and 3f), which may indicate that this is the stress-inducing range of phenol for the common duckweed, while its rhizosphere bacteria remain unaffected. Moreover, bacteria may act to some extent as a protective biological layer, minimizing the oxidative stress and cell wall disruption that occurs with exposure to higher doses of phenol [30]. Finally, all of these observations are consistent with the experiment with giant duckweed (Spirodela polyrrhiza), where phenol elimination by aseptically grown plants was negligible, whereas the elimination dependent on mixed culture of plants and rhizobacteria was significantly enhanced [9-10].

\section{Conclusions}

We have documented a mutually beneficial relationship between Lemna minor (the common duckweed) and the microbial community of its rhizosphere that could be used in bioremediation of phenol-contaminated waters. This relationship apparently allowed the duckweeds to survive $100 \mathrm{mg} / \mathrm{l}$ of phenol, which is considered a toxic concentration, and the elimination of $70 \%$ of starting $100 \mathrm{mg} / 1$ of phenol in only five days. Similarly to other Lemnaceae family members, our specimen of $L$. minor has a typically short doubling time and a high tolerance to phenol as well. The microbial population in its rhizosphere is probably specific to sampling site and the particular duckweed ecotype. The bacterial population of the rhizosphere must by analyzed in more detail (e.g., 16S rRNA sequencing and additional biochemical testing, including phenol tolerance), but the preliminary data presented in this paper are sufficient to propose the duckweed-microbial system (with emphasis on bacteria) as a promising platform for bioremediation of phenol-contaminated waters.

\section{Acknowledgements}

This research was financed by the Serbian Ministry of Science and Education, project No. TR37001. The authors would like to thank Nataša Miljković, MD, and Žarko Morača, MSc, for their unselfish support and constructive criticism.

\section{Conflict of Interest}

The authors declare no conflict of interest. 


\section{References}

1. APPENROTH K.J., BORISJUK N., LAM E. Telling duckweed apart: Genotyping technologies for the Lemnaceae. Chin. J. Appl. Environ. Biol. 19, 1, 2013.

2. WANG W., ET AL. The Spirodela polyrhiza genome reveals insights into its neotenous reduction fast growth and aquatic lifestyle. Nat. Commun. 5, 3311, 2014.

3. ZIEGLER P., SREE K.S., APPENROTH K.J. Duckweeds for water remediation and toxicity testing. Toxicol. Environ. Chem. 98, 1127, 2016.

4. ZIEGLER P., ADELMANN K., ZIMMER S., SCHMIDT C., APPENROTH K.J. Relative in vitro growth rates of duckweeds (Lemnaceae) - the most rapidly growing higher plants. Plant Biol (Stuttg). 17 (1), 33, 2015.

5. ZHAO Y., FANG Y., JIN Y., HUANG J., BAO S., FU T., HE Z., WANG F., ZHAO H. Potential of duckweed in the conversion of wastewater nutrients to valuable biomass: A pilot-scale comparison with water hyacinth. Biores. Technol. 163, 82, 2014.

6. MAHAR A., WANG P., ALI A., AWASTHI M.K., LAHORI A.H., WANG Q., LI R., ZHANG Z. Challenges and opportunities in the phytoremediation of heavy metals contaminated soils: A review. Ecotoxicol. Environ. Safety. 126, 111, 2016

7. ZHOU Y.R., LU Y.F., ZHANG H.L., SHI W.M. Aerobic denitrifying characteristics of duckweed rhizosphere bacterium RWX31. Afr. J. Microbiol. Res. 7, 211, 2013.

8. YAMAGA F., WASHIO K., MORIKAWA M. Sustainable biodegradation of phenol by Acinetobacter calcoaceticus P23 isolated from rhizosphere of duckweed Lemna aoukikusa. Environ. Sci. Technol. 44, 6470, 2010.

9. OGATA Y., TOYAMA T., YU N., WANG X., SEI K., IKE M. Occurence of 4-tert-butylphenol (4-t-BP) biodegradation in an aquatic sample caused by the presence of Spirodela polyrrhiza and isolation of a 4-t-BP-utilizing bacterium. Biodegr. 24, 191-202, 2013.

10. TOYAMA T., SEI K., YU N., KUMADA H., INOUE D., HOANG H, SODA S., CHANG Y.C., KIKUCHI S., FUJITA M., IKE M. Enrichment of bacteria possessing catechol dioxygenase genes in the rhizosphere of Spirodela polyrrhiza: a mechanism of accelerated biodegradation of phenol. Water Res. 43 (15), 3765, 2009.

11. Medical Management Guidelines for Phenol. Agency for Toxic Substances and Drugs Registry (ATSDR), available at: https://www.atsdr.cdc.gov/MMG/MMG. asp?id=144\&tid=27, 2017.

12. PAISIO C.E., TALANO M.A., GONZALES P.S., NOGUERA C.M., KURINA-SANZ M., AGOSTINI E. Biotechnological tools to improve bioremediation of phenol by Acinetobacter sp. RTE 01.4. Environ. Technol. 37, 2379, 2016.

13. PINDI P.K., YADAV P.R., KODAPARTHI A. Bacteriological and Physico-Chemical Quality of Main Drinking Water Sources. Pol. J. Environ. Stud. 22 (3), 825, 2013.

14. NEZIRI A., MALOLLARI I., PAHO E., PAMBUKU A. Persistent organic pollutants in Buna river basin groundwaters (Albania). J. Environ. Protect. Ecology. 15 (2), 405, 2014.

15. POPA M., GLEVITZKY M., POPA D. M., DUMITRIEL G.A. Study Regarding The Water Contamination And The Negative Effects On The Population From The Blaj Area, Romania. J. Environ. Protect. Ecology. 15 (4), 1543, 2014.
16. HAMIDOVIĆ S., TEODOROVIĆ S., LALEVIĆ B., JOVIČIĆC-PETROVIĆ J., JOVIĆ J., KIKOVIĆ D., RAIČEVIĆ V. Bioremediation Potential Assessment of Plant Growth-Promoting Autochthonous Bacteria: a Lignite Mine Case Study. Pol. J. Environ. Stud. 25 (1), 113, 2016.

17. JUN CHEN, LI ZHANG, QING JIN, CUIZHU SU, LEI ZHAO, XIAOXIANG LIU, SHUMENG KOU, YUJING WANG, MING XIAO. Bioremediation of phenol in soil through using a mobile plant-endophyte system. Chemosphere. 182, 194, 2017.

18. YANG L., WANG Y., SONG J., ZHAO W., HE X., CHEN J., XIAO M. Promotion of plant growth and in situ degradation of phenol by an engineered Pseudomonas fluorescens strain in different contaminated environments. Soil Biol. Biochem. 43 (5), 915, 2011.

19. PRAKASH P.K., LOH C.S. 9 - Plant tissue culture for biotechnology, In Plant Biotechnology and Agriculture, edited by Arie Altman and Paul Michael Hasegawa, Academic Press, San Diego, 13, 2012.

20. LI H., CHENG Z. Hoagland nutrient solution promotes the growth of cucumber seedlings under light-emitting diode light. Acta Agricult. Scand. 65 (1), 74, 2015.

21. BERTANI G. Lysogeny at Mid-Twentieth Century: P1, P2, and Other Experimental Systems. J. Bacteriol. 186 (3), 595, 2004.

22. COOKE F.J., SLACK M. 183 - Gram-Negative Coccobacilli, In Infectious Diseases (Fourth Edition), edited by Jonathan Cohen, William G. Powderly and Steven M. Opal, Elsevier, 1611, 2017.

23. VAN ECHELPOEL W., BOETS P., GOETHALS P.L.M. Functional Response (FR) and Relative Growth Rate (RGR) Do Not Show the Known Invasiveness of Lemna minuta (Kunth). PLoS ONE. 11 (11): e0166132, 2016.

24. ZHIVOTOVSKY O.P., KUZOVKINA J.A., SCHULTHESS C.P., MORRIS T., PETTINELLI D., GE M. Hydroponic Screening of Willows (Salix L.) for Lead Tolerance and Accumulation. Internat. J. Phytorem._13 (1), 75, 2010.

25. KITTIWONGWATTANA C., VUTTIPONGCHAIKIJ $\mathrm{S}$. Effects of nutrient media on vegetative growth of Lemna minor and Ladnoltia punctata in vitro and ex vitro cultivation. Meajo. Int. J. Sci. Technlog. 7, 60, 2013.

26. BIANCONI D., PIETRINI F., MASSACCI A., IANNELLI M.A. Uptake of Cadmium by Lemna minor, a (hyper?-) accumulator plant involved in phytoremediation applications. E3. Web. Conf.; Italy, 1, 2013.

27. KURNIK K., TREDER K., SKORUPA-KŁAPUT M., TRETYN A., TYBURSKI J. Removal of Phenol from Synthetic and Industrial Wastewater by Potato Pulp Peroxidases. Water, Air, Soil Poll. 226 (8), 254, 2015.

28. JEON J., BALDRIAN P., MURUGESAN K., CHANG Y. Laccase-catalysed oxidations of naturally occurring phenols: from in vivo biosynthetic pathways to green synthetic applications. Microb. Biotechnology. 5 (3), 3182, 2012.

29. CHHABRA G., CHAUDHARY D., SAINGER M., JAIWAL P.K. Genetic transformation of Indian isolate of Lemna minor mediated by Agrobacterium tumefaciens and recovery of transgenic plants. Physiol. Mol. Biol. Plants. 17 (2), 129, 2011.

30. HANEY C.H., SAMUEL B.S., BUSH J., AUSUBEL F.M. Associations with rhizosphere bacteria can confer an adaptive advantage to plants. Nat. Plants. 1 (6), 150, 2015. 
